\title{
Prevalence of self-reported reported diabetes and treatment in an urban slum of India
}

Sir,

International Diabetes Federation's fifth edition of diabetes atlas estimates that there are around 63 million people with diabetes in India, second only to China. ${ }^{[1]}$ Indians are more prone to develop diabetes due to their peculiar gene structure and lifestyle. ${ }^{[2]}$ Despite having so many persons with diabetes in the country there is no nationwide data available for India. ${ }^{[3]} \mathrm{A}$ study was conducted in an urban slum of Delhi, the national capital of India in 2005 to find out the prevalence of self-reported diabetes among females of age 18 years or above. The current treatment practices of these persons with diabetes were assessed. This was a community-based crosssectional study wherein the respondents were selected by systematic random sampling from the three blocks selected randomly from the six blocks covered by the health workers from the All India Institute of Medical Science, New Delhi. The operational definition of selfreported diabetes which we used was "any eligible lady saying that a health care professional has ever told her that she has diabetes mellitus." Any respondent who was using a prescription medication for lowering the blood sugar was said to be on treatment for diabetes. If the respondent was able to show a fasting blood sugar level of $\leq 126 \mathrm{mg} / \mathrm{dl}$ or post prandial blood sugar of $\leq 200 \mathrm{mg} / \mathrm{dl}$ report from a reputed laboratory done within last 6 months her blood sugar was reported be under control. A total of 480 eligible women were interviewed. The mean (SD) age of the respondents was $40.4(12.7)$ years. $247(51.5 \%)$ women reported to have their blood tested for sugar ever in their life time. When asked about the reason for blood sugar testing, majority $(35.8 \%)$ answered that they were pregnant and was advised by the health care provider as routine test. The prevalence of self-reported diabetes mellitus was 5.4\% (95\% CI: 3.6-7.8). Four more persons with diabetes were identified with the help of health workers working in the area for a long time and having a sound knowledge of the area and its residents. Further analysis was done in these 30 identified persons with diabetes. 27 $(90 \%)$ persons with diabetes showed some proof of their disease, either blood sugar report or medicines they were taking currently. $17(56.7 \%)$ of them were identified less than 5 years ago. Eighty percent of these identified persons with diabetes were taking wither oral hypoglycemic agent or the insulin. Out of 24 persons with diabetes whose recent blood sugar report was available, 10 (41.7\%, 95\% CI: 22.1-63.3) respondents' had their blood sugar under control. Only four persons with diabetes had glucometer in their home for regular monitoring of blood sugar. It can be concluded that around half of the persons with diabetes in the urban slum of India is undiagnosed and status of treatment and blood sugar control of diagnosed persons with diabetes is very poor in urban slums of India.

Ritesh Singh

Department of Community Medicine, College of Medicine and JNM Hospital, The West Bengal University of Health Sciences (WBUHS), Kalyani, West Bengal, India.

Address for the correspondence: Dr. Ritesh Singh, Department of Community Medicine, College of Medicine and JNM Hospital, The West Bengal University of Health Sciences (WBUHS), Kalyani - 741 235, West Bengal, India. E-mail: drriteshsingh@yahoo.com

\section{REFERENCES}

1. Diabetes Atlas $5^{\text {th }}$ edition, International Diabetes Federation. Available from: http://www.idf.org/sites/default/files/IDFAtlas5E_Detailed_Estimates_0.xls. [Last accessed on 2013 May 8].

2. Mohan V, Sandeep S, Deepa R, Shah B, Varghese C. Epidemiology of type 2 diabetes: Indian scenario. Indian J Med Res 2007;125:217-30.

3. Anjana RM, Ali MK, Pradeepa R, Deepa M, Datta M, Unnikrishnan R, et al. The need for obtaining accurate nationwide estimates of diabetes prevalence in India - Rationale for a national study on diabetes. Indian J Med Res 2011;133:369-80.

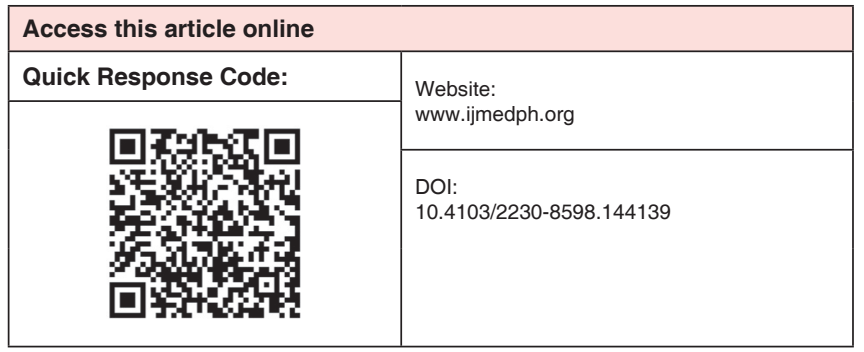

